\title{
Linguistic Syncopation: Meter-syntax alignment affects sentence comprehension and sensorimotor synchronization
}

\author{
Courtney B. Hilton ${ }^{123 *}$, Micah B. Goldwater ${ }^{2}$ \\ 1 Department of Psychology, Harvard University, \\ Cambridge, MA, 02138, United States \\ 2 School of Psychology, The University of Sydney \\ Sydney, NSW, 2006, Australia \\ 3 Sydney Centre for Language Research, \\ Sydney, NSW, 2006, Australia \\ * Corresponding author, email: courtney.bryce.hilton @gmail.com
}

\begin{abstract}
The hierarchical organization of speech rhythm into meter putatively confers cognitive affordances for perception, memory, and motor coordination. Meter also aligns with phrasal structure in systematic ways. In this paper, we show that this alignment affects the robustness of syntactic comprehension and discuss possible underlying mechanisms. In two experiments, we manipulated meter-syntax alignment while sentences with relative clause structures were either read as text (experiment $1, n=40$ ) or listened to as speech (experiment $2, n$ $=40$ ). In experiment 2 , we also measured the stability with which participants could tap in time with the metrical accents in the sentences they were comprehending. In addition to making more mistakes, sensorimotor synchronization was disrupted when syntactic cues clashed with the metrical context. We suggest that this reflects a tight coordination of top-down linguistic knowledge with the sensorimotor system to optimize comprehension.
\end{abstract}

Keywords: Meter, syntax, sensorimotor synchronization, sentence processing

\section{Introduction}

Speech has distinct rhythmic properties. Some of these rhythmic properties arise from a (quasi) periodic and hierarchically organised timing and accentuation structure called meter. Speech acoustics reflect meter (Ding et al., 2016; Goswami \& Leong, 2013; Tilsen \& Arvaniti, 2013), but it is not reducible to acoustic features. Meter is more internal and subjective. It can be thought of as a filter through which we perceive external rhythms (like speech or music), and as a scaffold around which we coordinate our own rhythmic actions when we speak, sing, or dance (Beier \& Ferreira, 2018; Hawkins, 2014; London, 2004; Port, 2003; Tilsen, 2019).

Meter influences perception, memory, and motor coordination (Boucher, 2006; Tilsen, 2011; Quené \& Port, 2005; see section 1.1 below). It also aligns systematically with the structure of speech and language. This alignment may serve a functional role: conferring more robust discrimination of speech sounds; more coordinated speaking; more effective language learning; and more memorable cultural knowledge. In this study, we specifically ask whether metrical 
alignment affects the robustness of syntactic comprehension and how this might relate to sensorimotor synchronization.

\subsection{Cognitive consequences of meter}

Speaking with predictable metrical timing attracts attention and sharpens perceptual discrimination (Dooling, 1974; Pitt \& Samuel, 1990; Quené \& Port, 2005; Cason \& Schön, 2012). And the stress patterns that punctuate speech rhythm affect perceptual grouping (Lee \& Todd, 2004; Martin, 1972). For example, one can be pushed between hearing "crisis turnip" or "cry sister nip" depending on the prior rhythmic context and the metrical expectancies they induce (Brown et al., 2011, 2015; Dilley \& McAuley, 2008; Kaufeld et al., 2019). Rhythm can even make syllables perceptually disappear altogether (Baese-Berk et al., 2019; Dilley \& Pitt, 2010; Morrill et al., 2014).

Speech spoken with regular stress patterns is easier to remember than when stresses are removed (Boucher, 2006; Robinson \& Robinson, 1977; Ryan, 1969) or when interstress timing exceeds a range of 0.5-2 seconds (Ghitza, 2017; Rimmele et al., 2020). This memory-boosting effect of metrical stress is also paralleled in music (Gorin et al., 2018; Mathias et al., 2015). And general mechanisms to explain such effects has been proposed based on the entrainment of neural oscillations (Ghitza, 2017; Hartley et al., 2016; Plancher et al., 2018). Consistent with this, children who tap in time with rhythms more accurately show stronger neural entrainment to speech as well as more robust auditory short-term memory (Woodruff Carr et al., 2014).

Metrically regular sentences are easier to speak than irregular ones, resulting in fewer speech errors (Tilsen, 2011) and more stable timing (Brown et al., 2017; Tilsen, 2011). Metrical perception is also impaired in populations with disordered speech fluency such as stuttering (Falk et al., 2015; Wieland et al., 2015) and expressive aphasia (Stefaniak et al., 2021). External metrical pacing has proven helpful in remediating these speech coordination difficulties (Toyomura et al., 2015), and even for improving gait in Parkinson's Disease (Benoit et al., 2014). Recent work suggests that neural entrainment may be a key mechanism underlying these relations to motor coordination (Cummins, 2009; Morillon et al., 2019).

\subsection{Meter-syntax alignment}

Does linguistic structure make use of these cognitive affordances? Meter (and prosody more generally) has strong relationships to linguistic structure and the broader pragmatics of linguistic communication (Calhoun, 2010; Cole, 2015; Ladd, 2008). One aspect of this relationship is the systematic tendency for syntax to influence the placement of the strongest metrical stress in the phrase (referred to as 'nuclear-stress' or 'phrasal stress'). In English, the rightmost content word typically receives this phrasal stress (e.g., "seven happy PUppies"). More generally (and crosslinguistically), stress follows the most deeply embedded syntactic constituent, which happens to be the rightmost for head-initial languages like English (Cinque, 1993). Exceptions (Bolinger, 1972; Ladd, 2008) drive ongoing theoretical debate (Selkirk, 2011; Wagner, 2010; Zubizarreta, 2014). For example, there are some open questions about whether prominence serving an information focus function (Breen et al., 2010) is represented metrically and whether the cues for this interact with those serving a more structural function (Kentner \& Vasishth, 2016; Wagner \& McAuliffe, 2019). Despite these nuances, the different proposals all acknowledge a systematic relation of meter to syntax in some form. 
Here we consider the possibility that this relation (hereafter 'meter-syntax alignment') arises to optimize the robustness of comprehension through the cognitive affordances of rhythm. That is, the cognitive demands of syntactic comprehension may themselves be rhythmically distributed over an utterance. Meter-syntax alignment may therefore, at least partly, serve to temporally coordinate meter (with the affordances it brings) to comprehending and producing syntactic sequences (with the demands it has).

\subsection{Evidence for a link}

A few key points of evidence help to motivate this hypothesis. First, syntactic structure cues the perception of phrasal stress over and above acoustic cues (Bishop et al., 2020; Cole et al., 2017, 2019; Kentner \& Vasishth, 2016; Wagner \& McAuliffe, 2019). This underscores not only the cognitively constructed nature of metrical perception - it is not acoustic - but crucially suggests that people actively seek out meter-syntax alignment. In light of our hypothesis, this may be seen as a form of perceptual expertise (Goldstone et al., 2015) that biases metrical perception towards interpretations which aid processing in some way. This top-down influence dovetails with other work showing that the perception of prosodic boundaries is also influenced by syntactic expectations independent from acoustic cues (Buxó-Lugo \& Watson, 2016; Cole et al., 2010).

105

106

107

108

109

110

Second, if meter serves a cognitive function then one would expect its presence even when language is not explicitly externalised, as in silent reading or inner speech. Building on the notion of implicit prosody (Bader, 1998; Breen, 2015; Fodor, 2002), a growing number of studies show that meter is both generated during silent reading and that it actively influences syntactic parsing (Breen, 2014; Breen et al., 2019; Breen \& Clifton, 2011, 2013; Kentner, 2012). Reading comprehension is also more robust when people imagine a vivid inner-voice (auditory perceptual simulation), and this is suspected to relate to a stronger activation of syntax-aligned prosodic representations (Zhou et al., 2019; Zhou \& Christianson, 2016).

Finally, if meter-syntax alignment optimizes processing then misalignment should have measurable consequences. Indeed, disruptions to meter affect the discrimination of morphosyntactic violations (Canette et al., 2020; Chern et al., 2018; Fiveash, Bedoin, et al., 2020; Kotz \& Schmidt-Kassow, 2015; Schmidt-Kassow \& Kotz, 2008); lexico-semantic integration (Rothermich et al., 2012; Rothermich \& Kotz, 2013); lexical priming (Gordon et al., 2011); and the comprehension of syntactically extended sentences with relative-clause structures (Roncaglia-Denissen et al., 2013).

However, a limitation of these studies is that they manipulate metrical regularity rather than alignment. For example, the effect of metrical regularity can be measured by contrasting the comprehension of sentences with a consistent stress pattern to sentences with unpredictable stress patterns. If the benefits of meter come by way of entrained neural oscillations, then irregular meter may simply provide a less predictable target to entrain to and thereby a less stable neuro-oscillatory substrate. This is distinct from the question of whether certain alignments (independent from regularity) optimize syntactic comprehension. The only study above that did manipulate alignment directly (Gordon et al., 2011) did so for simple sentence structures and only measured priming in a lexical decision task (in addition to neural measures). 


\subsection{The present study}

As we have seen, meter influences language processing in various ways. In particular, its alignment to syntactic phrase structure is systematic in both perception and production, and there is growing evidence that this might influence comprehension in ways that go beyond effects on low-level speech perception. The present study aims to provide a critical test of this putative effect of meter-syntax alignment that, in addressing previous limitations in the literature, both measures syntactic comprehension directly and manipulates meter-syntax alignment independently from metrical regularity. Experiment 1 does this for reading. Experiment 2 extends this to speech, while also measuring the effect of meter-syntax alignment on online processing through its effect on sensorimotor synchronisation.

\section{Experiment 1}

\subsection{Design}

\subsubsection{Manipulating syntactic complexity}

We used complex sentences with relative clauses for our primary materials. This means that there are two agents in the sentence that must be relationally bound to their grammatically licenced predicates. For example, in the sentence "the boy that helped the girl got an 'A' on the test" one has to determine 1) who helped whom, and 2) who got the 'A'. These bindings can then be probed using forced-choice prompts as a measure of syntactic comprehension (e.g., asking "did the girl help the boy?", to which a participant would respond "yes" or "no").

Complexity can be further manipulated through the extraction of the relative clause. For English speakers, object-extracted sentences are more difficult to process than subject-extracted sentences because of an increased memory load in tracking syntactic dependencies (Gibson, 1998; Gibson et al., 2005) and as a result of being less frequent in usage (Levy et al., 2012). By having these two levels of syntactic complexity, we are able to assess whether the effect of meter-syntax alignment interacts with syntactically induced memory load. If it does, this would be consistent with meter mediating the robustness of the sentence representation in short-term memory, and thus help to narrow down the interpretation of any congruity effect.

\subsubsection{Sentence materials}

We composed 48 English sentences, each from 12 monosyllabic words (these sentence materials were adapted and extended from those used in Fedorenko et al., 2009; some sentence-final words had two syllables). Each of these 48 sentences were arranged into versions with either subject- or object-extracted relative clauses: the only difference is word order. Each participant saw one of the two versions of each sentence in the experiment. A further 25 filler-sentences of assorted structure and length were also used to avoid the sentence structure from becoming too predictable (see for full materials: https://osf.io/42msj/)

\subsubsection{Manipulating meter-syntax alignment}

Congruent and incongruent meter-syntax alignments were defined for both sentence types according to the following process (figure 1). First, the sentences were divided into prosodic groups such that all major syntactic boundaries corresponded with a right edge of one of these groups (but not all prosodic edges had to correspond with syntactic boundaries). Second, in the 
congruent meter-syntax alignment, metrical accents were aligned with the right edge of each of these prosodic groups such as to form a regular meter. The incongruent condition was defined by shifting the congruent alignment 'to the left' by one metrical position.

For the subject-extracted sentences, this alignment formed a regular binary meter (stress every second syllable) for the noun phrase constituent and a ternary meter (stress every third syllable) for the verb phrase constituent. Enforcing metrical regularity, we rhythmically reduced the function words in the verb phrase (e.g., having "on the" have the same duration as "test") so that the whole sentence formed a regularly timed binary meter throughout (such reductions are common in natural speech, see: Martin, 1972; Brown, Pfordresher, Chow, 2017). The same procedure was applied for the object-extracted sentences, except that due to differences in sentence structure, a ternary meter was more parsimonious.

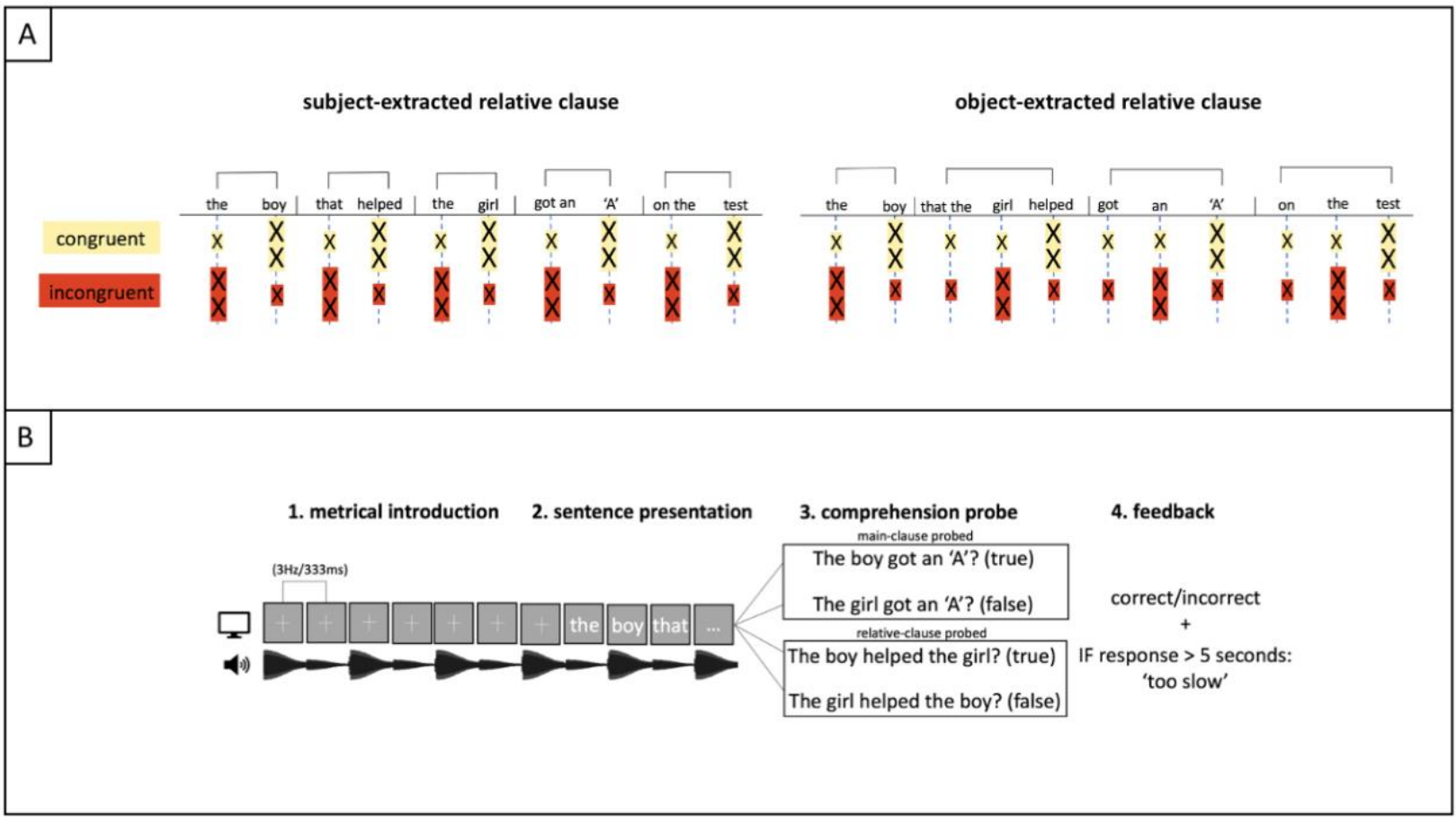

Figure 1: Information about Experiment 1. A) Definitions of congruent and incongruent meter-syntax alignment for both sentence types. The brackets above the sentence represent prosodic groups. The X's represent metrical accent, where one X is a weak beat and two X's a strong beat. The timing between each horizontally aligned X is equal. B) Schematic demonstrating the sequence of events in each main trail.

198 In other studies, meter is often manipulated by using sequences of words with different lexical stress patterns. For example, "SAlly is HOping to TRAvel to CAnada" forms a regular ternary pattern, versus "SAlly is aVOIding a TRIP to CAnada" forms an irregular meter (Tilsen, 2011). This approach cannot manipulate meter-syntax alignment independently from metrical regularity. Our approach was to hold the sentence materials constant across the different metrical conditions and instead manipulate meter with rhythmic auditory tones that accompany the 
sentence presentation (Cason et al., 2015; Cason \& Schön, 2012; Falk et al., 2017; Falk \& Dalla Bella, 2016).

These auditory stimuli were generated using a custom Python script and consisted of a $333 \mathrm{~Hz}$ pure tone in which a $3 \mathrm{~Hz}$ beat was induced by amplitude-modulating the signal with an asymmetric Hanning window with $80 \%$ depth and a 1:19 ratio of rise-to-fall time. Every second (binary meter) or every third (ternary meter) tone then received a further 50\% amplitude boost to cue strong beats.

\subsubsection{Experimental procedure}

Participants were seated at a chair in front of a computer in a quiet room and supplied with headphones adjusted to a comfortable listening volume. The experiment was run by a custom program written in Python. After an introduction to the task led by the experimenter, participants completed a series of practice trials and were encouraged to ask any clarifying questions. They were told that the experiment was about how rhythm affects reading and that they were to imagine their inner-voice speaking the sentences in the rhythmic pattern provided in each trial (after the experiment, all participants confirmed in an informal debrief that they had done this). They were also told that this rhythm might make comprehension easier or harder, and that this was part of the experiment: they should not ignore the rhythm. They then completed the main experiment as a single block interspersed with short breaks.

Participants began each trial by pressing the space key. A series of auditory tones then provided a metrical context that either aligned or misaligned with the following sentence, during which time participants attended to a fixation-cross centre screen (figure 1b). Next, the words began visually appearing in the place of the fixation cross as white text on a grey background synchronized to the continuing auditory tones until the sentence was finished. At the end of the sentence, the probe question appeared center screen (e.g. "the boy got an A?") and the participant responds as quickly as possible with either " $y$ " (yes) or " $n$ " (no) keys on a keyboard. Additionally, they were given the option of "d" (don't know) and encouraged to use this if they got distracted and did not register the sentence properly and would otherwise randomly guess; these were quite rare (across all participants: 27 during congruent trials, 37 during incongruent trials) and were discarded from the final analysis. If participants took longer than 5 seconds to respond, they were prompted to speed up on the next trial. Corrective feedback was given after each trial and participants were encouraged to balance speed with accuracy.

The participant saw one of four possible probe questions for each sentence, probing either the main or relative clause, and framing the question such that the correct answer could be either "yes" or "no". The sentence materials, and their assignment to syntactic complexity, metersyntax alignment, and probe-clause factors was balanced and randomized in each participant, as well as their order of presentation. Probe question type was also balanced and randomized in this way.

\subsubsection{Participants}

40 native English-speaking volunteers ( 20 female, 20 male) from the Sydney area took part in this study and were naive to which conditions were supposed to be the 'incongruent' ones. They were between 22 and 52 years of age $(\mathrm{M}=28.3, \mathrm{SD}=6.2)$. They had normal hearing, and 
normal or corrected vision, and no prior history of speech or language disorders. They provided written consent before commencing the experiment, and the protocol was approved by the

\subsubsection{Predictions}

The design manipulated factors of syntactic complexity (subject- or object-extracted constructions), meter-syntax alignment (congruent or incongruent alignments), and probed clause (main or relative clause): a 2 × 2 × 2 within-subjects factorial design. We expected metersyntax alignment to affect both the number of comprehension mistakes and length of response times, in line with other studies of prosody-syntax congruity (Kjelgaard \& Speer, 1999). Thus, we predicted main effects for all three factors: more comprehension mistakes and longer response-times for object-extracted sentences, relative-clause probes, and most importantly, incongruent meter-syntax alignments. Additionally, we predicted an interaction between metersyntax alignment and syntactic complexity: a stronger cost of misalignment for the more demanding sentence type (Fedorenko et al., 2009).

We preregistered our predictions and analysis plan (https://osf.io/42msj/), however, deviate subtly in a way that allows a fuller description of the data. We initially planned to analyse just the main-clause probe trials and to do so with a repeated-measures analysis of variance (we initially modelled our design and sentence materials on Fedorenko et al., 2009). However, we later we decided to analyze trials that probe the relative-clause in addition to the main clause. To account for this additional complexity, we used mixed-effects modelling rather than the planned repeated-measures analysis of variance. This change does not affect the significance of our results.

\subsection{Results}

\subsubsection{Comprehension}

2.2.1.1 Model selection Comprehension data (whether correct or incorrect on each trial) were analyzed using mixed-effects logistic regression with fixed-effects for congruency, relativeclause extraction, probed clause, probe-framing (whether the correct answer is 'yes' or 'no'), and the interaction between congruency and sentence-extraction. Random intercepts were included for participants and sentences. Responses that were more than 3 standard deviations from the mean in response times were excluded as outliers (11 trials, or $0.6 \%$ of the total trials).

2.2.1.2 Results All three hypothesized main effects were confirmed (figure 2; table 1), with more mistakes being made when there was an incongruent meter-syntax alignment, when the relative clause was probed, and when the sentence had an object-extracted relative-clause construction. The syntactic complexity by metrical alignment interaction was, however, not significant.

Table 1: Estimate of fixed effects for accuracy model

\begin{tabular}{lllll}
\hline & $\beta$ & $\begin{array}{l}\text { Std. } \\
\text { Error }\end{array}$ & Z value & $p$ value \\
\hline (Intercept) & 1.222 & 0.167 & 7.309 & $<0.001 * * *$
\end{tabular}




\begin{tabular}{lcccc} 
Congruency (incongruent) & -0.461 & 0.155 & -2.963 & $0.003 * *$ \\
RC extraction (subject) & & & & $<0.001 * * *$ \\
Probed clause (relative-clause) & 0.909 & 0.187 & 4.859 & $<0.001 * * *$ \\
Probe framing (positive) & -0.679 & 0.123 & -5.524 & $<.001 * * *$ \\
Congruency (incongruent) x RC extraction (subject) & 0.712 & 0.123 & 5.777 & 0.539 \\
\hline
\end{tabular}

\subsubsection{Response times}

2.2.2.1 Model selection Response times (RTs) were defined as the duration from the presentation of the probe question on the screen to the point at which the participant pressed a key to indicate their response. This was measured in seconds, then log-transformed. These data were analyzed using a linear mixed-effects model of the same basic structure as the comprehension model. Model comparison using a likelihood test preferred a model that included the interaction congruency and trial number $(\chi 2(2)=22.964, \mathrm{p}=<.001)$, so this was included.

2.2.2.2 Results All three main hypothesized effects are confirmed: slower response times for incongruent meter-syntax alignment, object-extracted sentences, and relative-clause probes (figure 2; table 2). Participants were also significantly faster when accepting the probe

304 (indicating 'yes') was the correct answer. For transparency we note that the crucial main-effect of meter-syntax alignment is only significant when the interaction between congruency and trial number is included in the model, which although provides a significant improvement to model fit, was not part of our original analysis plan.

Table 2: Estimate of fixed effects for response times model (in log-transformed seconds)

\begin{tabular}{lllll}
\hline & $\beta$ & $\begin{array}{l}\text { Std. } \\
\text { Error }\end{array}$ & t value & $p$ value \\
\hline (Intercept) & 0.774 & 0.052 & 14.951 & $<0.001 * * *$ \\
Congruency (incongruent) & 0.101 & 0.039 & 2.559 & $0.011^{*}$ \\
RC extraction (subject) & & & & \\
Probed clause (relative-clause) & -0.109 & 0.022 & -4.883 & $<0.001 * * *$ \\
Probe framing (positive) & 0.109 & 0.019 & 5.645 & $<0.001 * * *$ \\
Congruency (congruent) x Trial number & -0.110 & 0.019 & -5.660 & $<0.001 * * *$ \\
Congruency (incongruent) x Trial number & -0.001 & $<.001$ & -1.770 & 0.077 \\
\hline
\end{tabular}



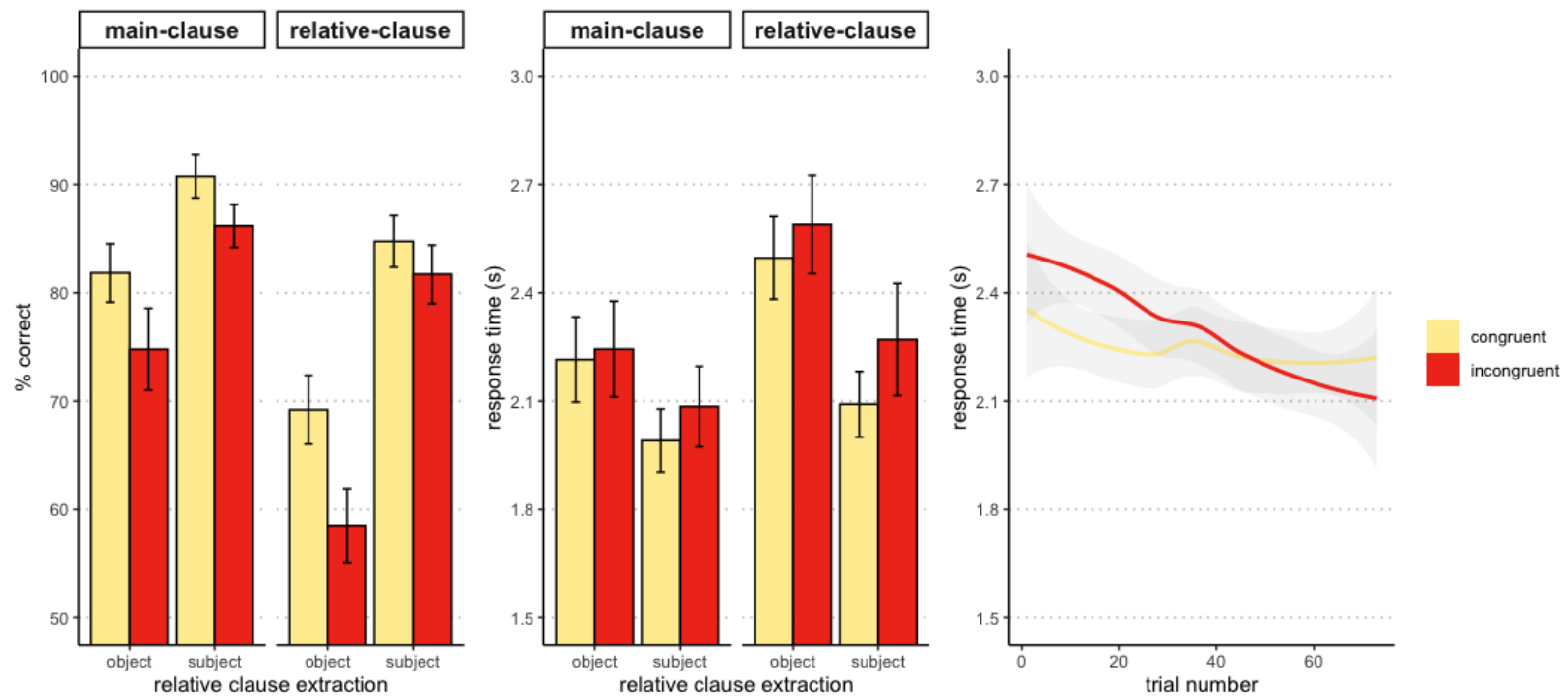

Figure 2: Results from experiment 1 show that meter-syntax congruency affects comprehension accuracy and response-times. Left: Accuracy. Middle: Response times. Right: Response times as a function of trials (although log-transformed response times were statistically analysed, un-transformed response times are shown here for interpretability). Error bars indicate standard error of the mean.

\subsection{Discussion}

In line with our predictions, participants made more comprehension mistakes and took longer to respond to comprehension probes when reading sentences with atypical meter-syntax alignment. However, this effect did not interact with syntactic complexity as we originally predicted.

Prior studies on meter and reading have investigated how prior text can induce metrical expectations that may clash with the processing of a target section (Breen \& Clifton, 2011, 2013; Kentner, 2012). Our study is unique in that it holds linguistic materials constant across conditions and instead manipulates meter through alignment with a rhythmic tone sequence. This allowed us to investigate the effect of metrical alignment independently from metrical regularity (meter was regular across all conditions). Additionally, this highlights how meter during reading is dynamically enacted and more than simply a concatenation of lexical stress patterns (consistent with: Zhou \& Christianson, 2016; Zhou et al., 2019).

A limitation of our design is that we assumed that words aligning with amplitude accented tones would be perceived as metrically strong. Metrical strength does not necessarily correspond to acoustic intensity in either music (Lerdahl \& Jackendoff, 1983) or language (Wagner \& McAuliffe, 2019). We think it unlikely, but it is possible that some participants were perceiving metrical accent in different positions than assumed in our experiment, driven by their own intuitions for implicit prosody (Fodor, 2002), thus contributing additional variability to our results. 
instead presented as auditory speech. To ensure that participants were perceiving the meter as we intended, we instructed them to tap their finger in time with the strong beat both during the metrical introduction to each trial and to continue such tapping during the subsequent speech stimuli. Further extensions to the design were also employed, which are now described.

\subsection{Experimental design}

\subsubsection{Meter-syntax alignment}

Experiment 2 expanded to three levels of meter-syntax alignment for each sentence type. To achieve this, both sentence types were set to a ternary meter. The congruent condition, as before, had the metrically strong beats align with the right-edge of the syntactic phrases. The other two incongruent conditions then aligned this strong beat with either a group-medial position (incongruent-1; this was the same as the incongruent condition from experiment 1) or with the left-edge of the prosodic group (incongruent-2; see figure 3a).

A limitation of the adopted design is that in order to fit the subject-extracted structures into a ternary meter (and thus to allow three possible alignments) certain rhythmic compromises were required that confound comparisons regarding syntactic complexity. Specifically, the bolded words in, for example, "the boy that helped .." were followed by a silence (with the duration of a syllable) to fit the ternary meter (see figure $3 \mathrm{a}$ ). This confounds the interpretation of the syntactic complexity effect and congruity by complexity interaction; however, this was not the focus of this study and it does not confound the central congruity manipulation. The subjectextracted sentences here serve to show the robustness of the effect to different structures and to ensure structure was not predictable between trials.

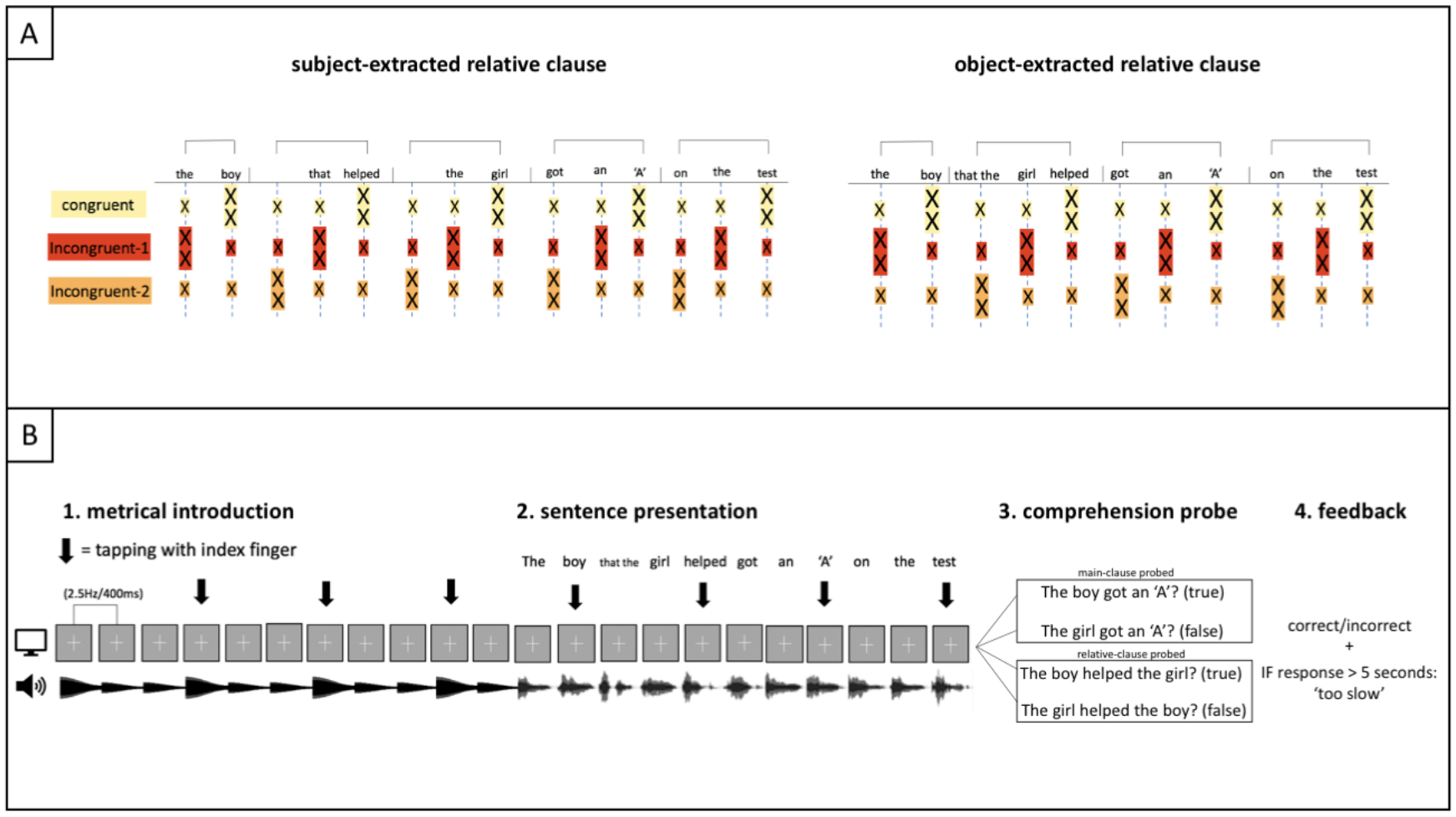


Figure 3: Information about experiment 2. A) The same procedure determines meter-syntax alignment (as with Figure 1) but with three alignment conditions. The brackets above the sentence represent prosodic groups. The X's represent metrical accent, where one $\mathrm{X}$ is a weak beat and two X's a strong beat. The timing between each horizontally aligned $\mathrm{X}$ is equal. B) Trial schematic.

\subsubsection{Sentence materials and speech synthesis}

To accommodate the additional meter-syntax alignment conditions, ensuring enough trials per condition per participant, the original 48 sentences and probes from experiment 1 were extended to a new total of 72 sentences with the same basic properties.

Speech stimuli were synthesized using a custom Python script. This script first generated audiofiles for each word in the sentence individually (using Google's text-to-speech API: the voice of Google Translate). These individual speech sounds were then preprocessed to standardize duration, amplitude, and pitch qualities in the signal. Finally, they were strung together into a whole sentence with a constant syllable rate of $2.5 \mathrm{~Hz}$ (this slower presentation-rate was arrived at through piloting). This synthesis procedure increases reproducibility and reduces the possibility of confounding prosodic cues. Auditory beat stimuli used for the metrical introduction (figure $3 \mathrm{~b}$ ) were the same as experiment 1 except for now being at the slower $2.5 \mathrm{~Hz}$ tempo.

\subsubsection{Sensorimotor synchronization}

To assess the effect of meter-syntax alignment on sensorimotor synchronization, we measured how accurately participants tapped in time with the speech they were trying to comprehend (figure 3b). Their tapping was recorded on a MIDI drum-pad (Korg Nanopad) that registered timing and pressure of each tap, and they used their dominant index-finger. Participants received no auditory feedback from their tapping and volume was calibrated such that the physical sound of the tapping could not be heard.

To estimate the effect of meter-syntax alignment on sensorimotor synchronization we had to control for low-level rhythmic properties of the speech stimuli. We did this by comparing the tapping variability to the speech stimuli to rhythmically matched control stimuli that were rendered as amplitude-modulated puretones instead of speech (see supplementary figure 1). Participants were presented six trials for each of the control rhythms. The start of each of these trials had an additional accented bass tone which served to indicate where the participant should tap. This dropped out after four repetitions, leaving the participant to continue the pattern on their own.

\subsubsection{Experimental procedure}

The same procedure as experiment 1 was used, except that participants were now required to tap on a drum-pad in time with metrically accented beats. They were told that the experiment was investigating how this rhythm affects their comprehension, so were to not ignore the rhythm. Participants were given instructions on tapping and a series of practise tasks, then completed the non-linguistic rhythm control task in a single block (lasting $~ 15 \mathrm{mins}$ ). Each participant saw a unique randomized order of trial types.

After the non-linguistic metrical rhythm section, participants completed the 72 sentences of the main language task in a single block (interspersed with short breaks). They were encouraged to balance attention equally between the language aspect of the task and tapping as accurately as they could with the beat. The trial structure during the main experimental block was similar to 
experiment 1, except that the metrical tones from the introduction to each trial stopped playing while the auditory speech played (see figure 3). Importantly, this meant that there were no acoustical cues to meter during sentence presentation. Thus, it was presumed that the metrical percept during the speech would be induced by preceding distal metrical context, and reinforced and maintained by the participant's finger tapping.

\subsubsection{Participants} 40 new English-speaking volunteers from the Sydney area (17 female, 23 male) were recruited, who met the same basic requirements as in experiment 1 . They were between 21 and 65 years of age $(\mathrm{M}=29.3, \mathrm{SD}=8.6)$.

\subsubsection{Predictions}

3.1.5.1 Meter-syntax alignment We predicted that the congruent alignment would result in fewest comprehension mistakes and fastest response times, as compared to either incongruent-1 or incongruent-2 alignments. In adjudicating between the two incongruent alignments, we note that incongruent-1 places the metrical stress in a medial position in each group ("on THE test") and incongruent-2 a left-aligned position ("ON the test"). Prior theory notes a tendency for aligning prominences to edges of metrical constituents (see: Prince, 1983), thus we weakly predict incongruent- 1 to have a stronger cost on comprehension over incongruent-2.

3.1.5.2 Sensorimotor synchronization We also predicted that meter-syntax alignment would affect the variability of sensorimotor synchronization, such that congruent alignment would show the least variable tapping and incongruent- 1 the most variable.

\subsection{Results}

\subsubsection{Comprehension}

3.2.1.1 Model selection The same analysis approach is used here as in experiment 1, with model selection procedures leading to the same basic structure. Additionally, including a predictor based on sensorimotor synchronization (tapping ratio; see section 3.2.3) did not improve model fit $(\chi 2(1)=1.376, p=0.241)$, however, including an interaction between this synchronization metric and congruency did improve model fit $(\chi 2(1)=6.422, \mathrm{p}=0.011)$.

3.2.1.2 Results The results replicate those of experiment 1: more mistakes were made for (both) the incongruent conditions, object-extracted sentences, and when the relative-clause was probed (figure 4; table 3). While the negative effect on comprehension was numerically larger for the incongruent- 1 alignment over incongruent- 2 , this difference was not itself statistically significant $(\chi 2(1)=2.408, \mathrm{p}=0.121)$.

Table 3: Estimate of fixed effects for accuracy model

\begin{tabular}{lllll}
\hline & $\beta$ & $\begin{array}{l}\text { Std. } \\
\text { Error }\end{array}$ & Z value & $p$ value \\
\hline (Intercept) & 0.957 & 0.221 & 4.334 & $<0.001 * * *$
\end{tabular}




\begin{tabular}{|c|c|c|c|c|}
\hline Congruency (incongruent-1) & -0.516 & 0.118 & -4.370 & $<0.001 * * *$ \\
\hline Congruency (incongruent-2) & -0.418 & 0.118 & -3.555 & $<0.001 * * *$ \\
\hline RC extraction (subject) & 0.718 & 0.256 & 2.807 & $0.005 * *$ \\
\hline Probed clause (relative clause) & -0.514 & 0.093 & -5.517 & $<0.001 * * *$ \\
\hline Probe framing (positive) & 0.584 & 0.093 & 6.253 & $<0.001 * * *$ \\
\hline $\mathrm{RC}$ extraction (object) $\mathrm{x}$ tapping ratio & 0.223 & 0.128 & 1.795 & 0.073 \\
\hline $\mathrm{RC}$ extraction (subject) $\mathrm{x}$ tapping ratio & -0.191 & 0.159 & -1.201 & 0.230 \\
\hline
\end{tabular}

455

\subsubsection{Response times}

3.2.2.1 Model selection Again, we adopt the same basic model structure as for experiment 1 for analysing log-transformed response times, also rejecting outliers that fall more than 3 standarddeviations from mean. However, unlike with the comprehension accuracy results, adding tapping variability as a predictor to the model did not significantly improve model fit $(\chi 2(1)=0.833, \mathrm{p}=$ 0.362 ) nor did its interaction with congruency $(\chi 2(3)=4.387, p=0.223)$. Trial number did improve model fit $(\chi 2(1)=41.072, \mathrm{p}=<0.001)$ and including an interaction between this and congruency improved the model further $(\chi 2(2)=6.310, p=0.043)$. However, including this interaction explained away the variance of the effects of congruency and probe framing, and likelihood tests preferred the simpler models that then dropped these from the model. We adopt this latter model, but the alternative without the congruency by trial number interaction shows a significant main effect of congruency (incongruent-1: $\beta=0.054, \mathrm{SE}=0.018, \mathrm{t}=3.094, \mathrm{p}=$ 0.002 ; incongruent $-2: \beta=0.040, \mathrm{SE}=0.018, \mathrm{t}=2.286, \mathrm{p}=0.022$ ).

3.2.2.2 Results The results replicate the fixed effects of syntactic complexity, probed clause, and syntactic complexity (figure 4; table 4). To compare the magnitude of the congruency by trialnumber interaction we used a Wald chi-square test. The rate of improvement in response time over trials was significantly greater for the congruent alignment over incongruent- $1(\chi 2(1)=$ $16.737, \mathrm{p}=<0.001)$ or incongruent- $2(\chi 2(1)=13.482, \mathrm{p}=<0.001)$. This interaction with trial number is also visualized in figure 4 .

Table 4: Estimate of fixed effects for response time model (log normalized units)

\begin{tabular}{lllll}
\hline & $\beta$ & $\begin{array}{l}\text { Std. } \\
\text { Error }\end{array}$ & t value & $\mathrm{p}$ value \\
\hline (Intercept) & 0.903 & 0.039 & 22.860 & $<.001 * * *$ \\
RC extraction (subject) & -0.093 & 0.017 & -5.381 & $<.001 * * *$ \\
Probed clause (relative clause) & & & & \\
Probe framing (positive) & 0.098 & 0.014 & 6.943 & $<.001 * * *$ \\
Congruency (congruent) x Trial number & -0.053 & 0.014 & -3.712 & $<.001 * * *$ \\
& -0.003 & $<.001$ & -7.055 & $<.001 * * *$
\end{tabular}



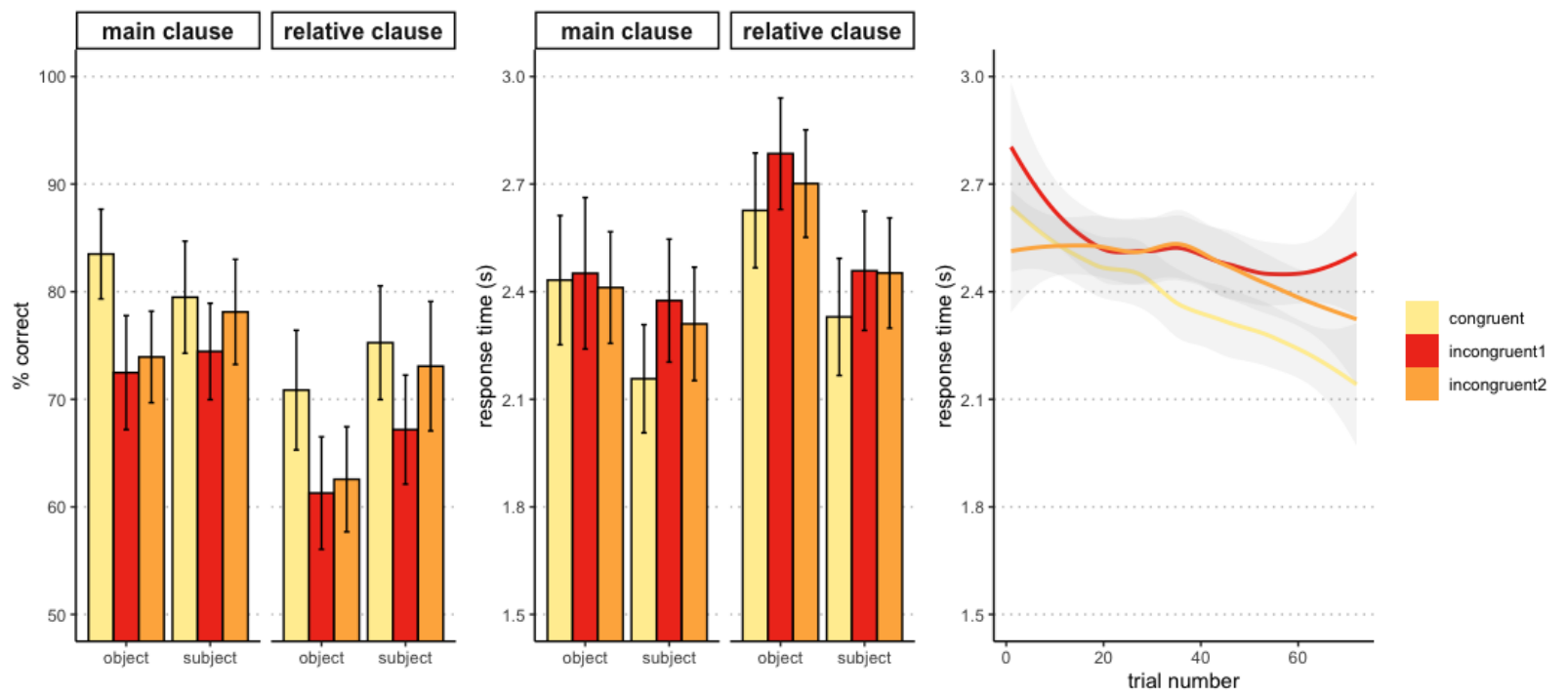

Figure 4: Results from experiment 2 show significant effects of meter-syntax congruency on comprehension accuracy and response times. Left: accuracy results, Middle: response time results (as before, showing untransformed units for interpretability),

Right: showing how response times change over the course of the experiment. Error bars indicate standard error of the mean.

\subsubsection{Sensorimotor synchronization}

Finally, to assess the effect of meter-syntax alignment on sensorimotor synchronization we analysed the ratio of tapping to speech to tapping to rhythmically matched non-linguistic tones: scores greater than 1 indicate more variable tapping over and above that contributed by basic rhythmic properties. Starting with the non-linguistic rhythms, we first computed the asynchronies between each tap and the target beat. Standard deviations were then computed for each trial and then averaged within each participant and for each of the four rhythm types (figure 4a). The same procedure was then applied to the tapping in time with speech during the main task, except prior to averaging, the trial-level variability scores were divided by the conditionaveraged non-linguistic rhythm scores, yielding the tapping ratio score. The final participantlevel averages are shown in figure 6.

3.2.3.1 Model selection These trial-level ratio scores were analysed using a linear mixed effects model with fixed effects of meter-syntax congruency and relative-clause extraction, and random intercepts for participants. Including trial number did not improve model fit $(\chi 2(1)=1.556, \mathrm{p}=$ $0.212)$, nor did the interaction between congruency and syntactic complexity $(\chi 2(1)=1.012, \mathrm{p}=$ $0.603)$.

3.2.3.2 Results Confirming our predictions, there was significantly greater tapping variability for both incongruent alignments over the congruent alignment (figure 6; table 5). Incongruent-1 alignment was also significantly more variable than the incongruent- 2 alignment $(\chi 2(1)=16.465$, $\mathrm{p}=<.001$ ). Additionally, there was a significant effect of syntactic complexity, such that tapping in time with object-extracted sentences contributed additional variability (presumably because 
these sentences more challenging to understand and pulled more attention away from synchronization).

Table 5: Estimate of fixed effects for tapping ratio score

\begin{tabular}{lccccc}
\hline & $\beta$ & $\begin{array}{l}\text { Std. } \\
\text { Error }\end{array}$ & $\mathrm{t}$ value & $\mathrm{p}$ value \\
\hline Intercept) & 1.285 & 0.066 & 19.473 & $<0.001 * * *$ \\
Congruency (incongruent-1) & & 0.249 & 0.035 & 7.048 & $<0.001 * * *$ \\
Congruency (incongruent-2) & & & & & \\
RC extraction (subject) & 0.098 & 0.036 & 2.738 & $0.006 * *$ \\
\hline
\end{tabular}

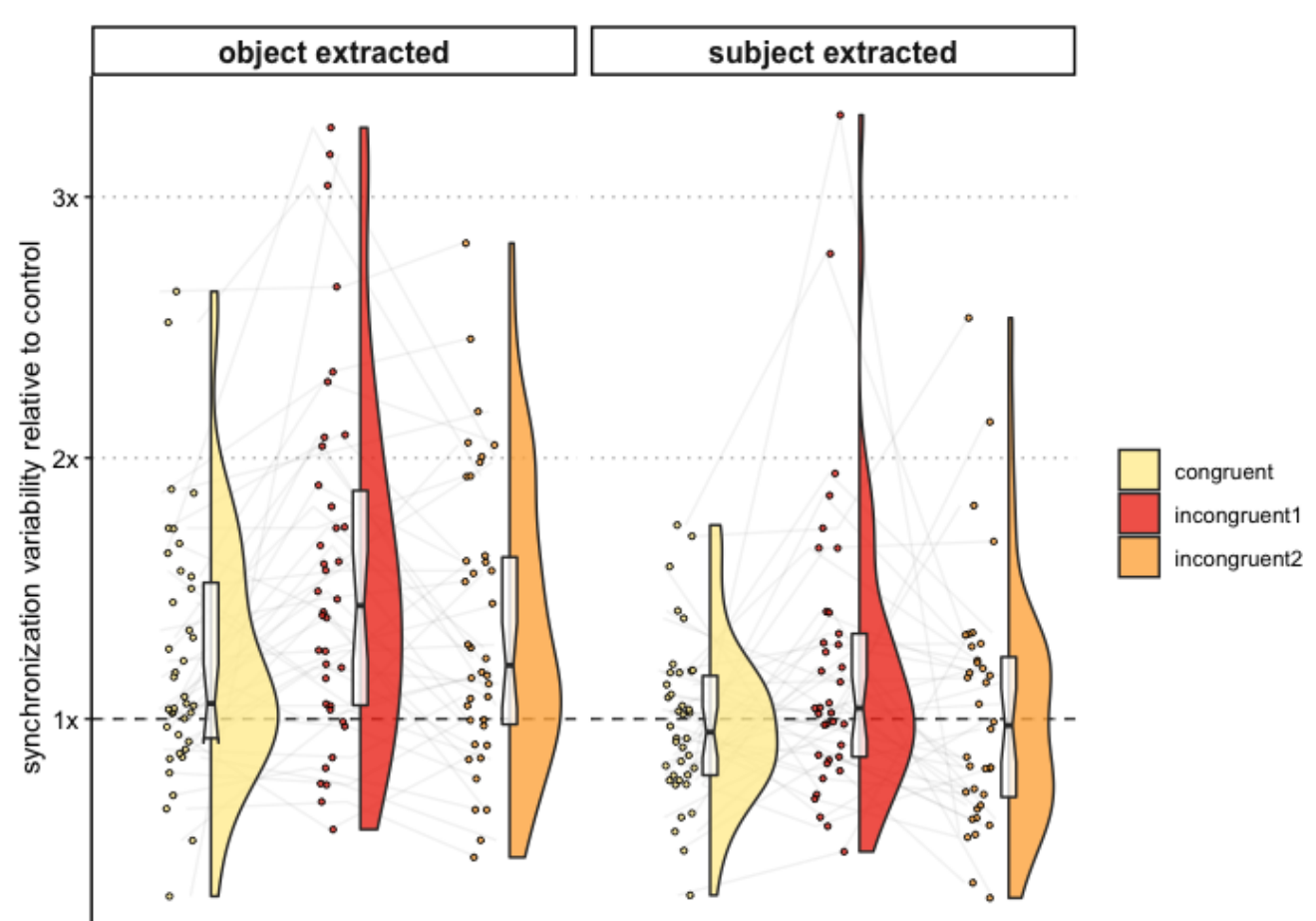

Figure 5: Sensorimotor synchronization results for experiment 2. Incongruent meter-syntax alignment resulted in more variable synchronization with the speech stimuli. Synchronization variability is expressed as the ratio of tapping with the speech stimuli over the control non-linguistic stimuli (i.e., a value of 1 indicates equivalent variability for speech and control rhythms). The points indicate averages for each participant; the gray lines connecting the points indicate scores for the same participant; the half-violins are kernel density estimations; and the boxplots represent the medians, interquartile ranges, and $95 \%$ confidence intervals (indicated by the notches). speech (rather than visual text), we showed that congruent meter-syntax alignment resulted in better performance than alignment shifts 'to the left' (incongruent-2) or 'to the right' 
was only statistically significant for the sensorimotor synchronization results, however, the trend was fairly consistent across the different measurements (congruent > incongruent-2 > incongruent-1). Should these differences turn out to be robust, they would provide a useful empirical target to constrain theory on why metrical alignment influences syntactic comprehension. Regardless, the difference between the congruent alignment and both incongruent alignments was robust for all measurements in the experiment, consistent with our primary hypothesis.

The effect of whether the comprehension probe targeted the main or relative clause was also replicated. While not theoretically relevant to meter-syntax alignment, this effect appears to be strong and robust at least within the current paradigm and from what we can gather, surprisingly few studies have addressed this topic (Lowder \& Gordon, 2014; Newman et al., 2009).

Unlike experiment 1 , we additionally had participants tap their finger in time with the metrical beat. This was partly to ensure that participants were perceiving the intended metrical alignment by having them externalise their perception of the strong beats. But more interestingly, this also allowed us to test whether meter-syntax alignment affected sensorimotor synchronization: it did.

Why might the stability of tapping be affected by the alignment of meter and syntax? We suspect this is caused by conflicting metrical cues. One metrical cue comes from the metrical introduction of each trial induced by timing and accentuation patterns (reinforced by finger tapping). The conflicting metrical cue arises from syntactic predictions (Levy, 2008), which bias the perception of metrical prominence toward the syntactically expected position (Bishop et al., 2020; Cole et al., 2019). Additional top-down inhibition may therefore be required to resolve the conflict and maintain sensorimotor coordination. Like with other congruity effects, the difficulty in inhibiting this automatic syntax-driven metrical reflex likely then explains the effect observed here.

While tapping in time with speech may seem like an artificial activity that could distract from comprehension, prior research shows that it can boost the perception of speech (Falk et al., 2017; Falk \& Dalla Bella, 2016) and audition generally (Morillon \& Baillet, 2017). And while people do not normally tap along with speech, they do frequently use 'beat gestures' implemented by rhythmic hand movements, which can affect metrical prominence perception (Krahmer \& Swerts, 2007) and syntactic parsing (Biau et al., 2018; Holle et al., 2012).

It is evident, however, that some of the variance in tapping stability comes from balancing attention between tapping and comprehending as shown by more challenging sentence structures predicting more variable tapping (table 5). This is consistent with prior work suggesting that topdown aspects of syntax and meter are controlled by a shared attentional resource (SchmidtKassow \& Kotz, 2008). Despite this, this is orthogonal to the main meter-syntax alignment effects of interest here.

Concerns may also be had about the strictly isochronous speech stimuli and whether the results here would generalize to more rhythmically variable and naturalistic speech. First, we note that many naturalistic modes of speaking do have stricter timing, especially joint-speech (Cummins, 2020). More pertinently, we agree with others who have argued that the rhythmic idiosyncrasies 
of conversational speech do not represent a departure from metrical structure but rather a shift in the balance of top-down and bottom-up cues that support it (Beier \& Ferreira, 2018; see also Hawkins, 2014). Thus, although induced differently in naturalistic speech, we see no reason to think that the effects of meter would be any different.

\section{General discussion}

Across both experiments, we found that the alignment of meter with phrase structure affected syntactic comprehension. This effect was robust for whether sentences were rhythmically read (experiment 1) or listened to as speech (experiment 2). Comprehension was optimal when meter aligned with syntax in the typical way for English phrases (stress on the rightmost content word of prosodic phrase); There were more comprehension mistakes and lengthier response times when the alignment deviated from this linguistic norm. Metrical regularity was held constant in all cases.

The second experiment also showed that misaligning meter and syntax resulted in more variable sensorimotor synchronization. This provided an online measure of meter-syntax congruity during sentence processing, complimenting the offline comprehension measures (accuracy and response times) after sentence presentation. Interpreting this difference in variability, we suggest an interference between an ongoing metrical representation and automatic, hard to inhibit, metrical reflexes tethered to syntactic predictions: a 'metrical Stroop effect'.

We did not find an interaction between meter-syntax congruity and syntactic complexity. We had originally intended this as a test of whether congruity affects structural integration and its underlying memory-based processes. Although our data fail to support this hypothesis, it does not rule it out as the effect could be quite subtle. Roncaglia-Denisson and colleagues (2013), for example, only found a meter-by-syntax interaction (with their metrical regularity manipulation) in the more sensitive neural data (in the P600; an electrophysiological marker of structural integration), and did not find an interaction in the behavioral data.

Additionally, the relative difficulty of our two sentence types may not relate as strongly to memory processes as we assumed. Specifically, object-extracted relative clause structures may be more difficult to process for English speakers because of their rarity in usage and therefore their low structural plausibility (Levy et al., 2012; Zhou et al., 2018), rather than being more difficult because of intrinsic structural properties (Gibson, 1998; Gibson et al., 2005). If this is true, our interaction is not so clearly expected: consistent with our result. Further research is needed.

We now turn to possible explanations for the main effect of congruity: Why are certain alignments better than others? As discussed in the introduction, meter is thought to have cognitive affordances for perception, memory, and motor coordination. Dynamic attending theory (Large \& Jones, 1999; Pitt \& Samuel, 1990) and related theories of neural oscillations and entrainment (Hartley et al., 2016; Henry \& Herrmann, 2014; Lakatos et al., 2008; Morillon et al., 2019; Rimmele et al., 2018) have emerged as viable frameworks for making sense of how and when these affordances arise. 
In the present study, it seems unlikely that the observed differences in syntactic comprehension were the result of metric modulations of low-level perception. For example, such that words aligned to strong beats were perceived more acutely. Our sentence materials were designed to minimize lexical ambiguities, to be morphologically as simple as possible, and to contain no additional prosodic information that could bias interpretation.

A more likely possibility is that meter affected comprehension by modulating lexical access and accessibility in memory rather than (just) the acuity of perceptual details. Metrically accented syllables make contact with lexical representations quicker in online processing, and are more accessible in short-term memory in offline processing (Gow \& Gordon, 1993). These effects are also reflected in neural markers of lexical integration (den Ouden et al., 2016; RoncagliaDenissen et al., 2013; Rothermich et al., 2012; Rothermich \& Kotz, 2013). Similar effects are also found for how metrical rhythm modulates memory for non-linguistic items (Hickey et al., 2020; Jones \& Ward, 2019; Plancher et al., 2018; Thavabalasingam et al., 2016).

How might this explain the differences in syntactic comprehension observed in our study? Across both experiments, the congruent conditions align metrical accent to only content words (e.g., "the BOY that the girl HELPED got an 'A' on the TEST"), whereas the incongruent conditions align mainly with function words (e.g., "THE boy that_the GIRL helped got AN 'A' on THE test"). Function words are relatively predictable given content words, but the opposite is not true: 'boy girl helped' is comprehensible but 'the that the' is not. Therefore, a stronger lexical activation and memory trace for more informative words in a sentence representation may support more robust comprehension and contribute to the pattern of results we observed (Aylett $\&$ Turk, 2004).

An alternative (potentially complimentary) explanation stems from how meter is implicated in serial-order short-term memory. Serial-order is thought to be cognitively represented by associating memory items with a temporal context signal arising from an entrained neural oscillator during encoding ( $\mathrm{Ng} \&$ Maybery, 2002). A recent model extends this to a hierarchy of such oscillators (Hartley et al., 2016) in a way that resembles the hierarchy of oscillators thought to underly meter (Hawkins, 2014; Port, 2003).

How might this explain our results? Metrical rhythm not only boosts serial-order recall generally, but it also changes the structure of memory confusions such that transpositions of order are more likely between rhythmic groups for items in the same metrical position than adjacent items in the same group (Gorin et al., 2018; Mathias et al., 2015). And within groups, memory is most robust at the beginning and end and least robust in the middle (Hartley et al., 2016; Hurlstone, 2019). Thus, the tendency to align metrical stress to the most deeply embedded syntactic constituent (Cinque, 1993) may function to distribute the pattern of serial-order robustness over a phrase in a way that is optimal for syntactic comprehension: ensuring that memory confusions are least likely to result in corrupted interpretations.

Finally, a temporal window for integrating sequence information into memory chunks may also be driven by entrained neural oscillations (Ghitza, 2017; Rimmele et al., 2020). Such temporal constraints appear to shape syntactic parsing (Meyer et al., 2017; Schremm et al., 2015, 2016) and sensorimotor synchronization (Mates et al., 1994). It is possible, therefore, that meter-syntax 
alignment affects syntactic comprehension by pushing around this window such that non-local dependencies are more-or-less likely to be integrated into the same memory chunk.

It remains for future research to disentangle and adjudicate between these possible mechanisms. Regardless of the mechanism(s) involved, our result highlights the importance of meter for linguistic processing beyond the more established effects on low-level perception. This has implications for a number of theoretical and applied areas.

Children with developmental language disorders (such as dyslexia) are thought to have impaired metrical entrainment and sensorimotor synchronization abilities, in both linguistic and musical contexts (Colling et al., 2017; Cumming et al., 2015; Fiveash, Schön, et al., 2020; Huss et al., 2011). They are also less sensitive to the alignment between meter and syntax (Richards \& Goswami, 2019). We speculate that interventions could have efficacy in targeting more directly this alignment between rhythm and (top-down) sentence structure.

In language learning more generally, a recent study by Blanco-Elorrieta and colleagues (BlancoElorrieta et al., 2020) compared the ability to discriminate speech in noise for both native and second-language speakers. They showed that linguistic ability not only makes comprehension more robust, but that it tracks with the ability to use top-down linguistic knowledge to drive neural entrainment to the speech signal. This mirrors our claim that syntactic predictions drive metrical predictions to enhance processing.

This importance of rhythm also underscores parallels with music. Gordon and colleagues (Gordon et al., 2015), for example, found that for typically developing children, the ability to discriminate metrical rhythms in a musical context was a strong predictor of grammatical development, even after controlling for non-verbal IQ, socioeconomic status, and prior musical abilities. These data are consistent with the claim that music and language play a mutually supportive role during development (Brandt et al., 2012; François et al., 2013), and that embedding speech in music benefits language learning (Schön et al., 2008; Vanden et al., 2020). Child-directed speech, song, and literature also has particularly emphasised metrical and musical qualities (Falk \& Kello, 2017; Moser et al., 2020) and often consistently aligns this with syntactic phrase structure (Breen, 2018).

In conclusion, we have shown that the alignment of meter to syntax affects the robustness of syntactic comprehension. This is important because meter (and its underlying neuro-oscillatory substrate) is often thought of as simply modulating low-level perceptual discrimination (Niebuhr, 2009; Pitt \& Samuel, 1990; Quené \& Port, 2005). But this result highlights its relevance to deeper aspects of cognitive processing. The synchronization results further highlight how topdown syntactic knowledge drives adaptive metrical reflexes. This likely relates to our spontaneous tendency for 'beat gesture' while we speak. We suggest that this reflects how our sensorimotor system is tuned through experience to optimize syntactic comprehension.

\section{Acknowledgements}

We thank the reviewers (Kiel Christianson and three anonymous) whose input greatly helped us in improving the manuscript. Thanks also to Rie Asano and Sam Mehr for comments on an early draft, as well as anonymous reviewers and audience from the 2019 Cognitive Science Society 
710

711

712

713

\section{References}

715

716

717

718

719

720

721

722

723

724

725

726

727

728

729

730

731

732

733

734 sectors.

conference who provided early feedback on some of this data. We also thank Peter Keller for advice on aspects relating to recording finger tapping in experiment 2 . This research did not receive any specific grant from funding agencies in the public, commercial, or not-for-profit

Aylett, M., \& Turk, A. (2004). The smooth signal redundancy hypothesis: A functional explanation for relationships between redundancy, prosodic prominence, and duration in spontaneous speech. Language and Speech, 47(1), 31-56.

https://doi.org/10.1177/00238309040470010201

Bader, M. (1998). Prosodic Influences on Reading Syntactically Ambiguous Sentences. In J. D. Fodor \& F. Ferreira (Eds.), Reanalysis in Sentence Processing (pp. 1-46).

Baese-Berk, M. M., Dilley, L. C., Henry, M. J., Vinke, L., \& Banzina, E. (2019). Not just a function of function words: Distal speech rate influences perception of prosodically weak syllables. Attention, Perception, and Psychophysics, 81(2), 571-589. https://doi.org/10.3758/s13414-018-1626-4

Beier, E. J., \& Ferreira, F. (2018). The temporal prediction of stress in speech and its relation to musical beat perception. Frontiers in Psychology, 9(APR), 1-6. https://doi.org/10.3389/fpsyg.2018.00431

Benoit, C. E., Dalla Bella, S., Farrugia, N., Obrig, H., Mainka, S., \& Kotz, S. A. (2014). Musically cued gait-training improves both perceptual and motor timing in Parkinson's disease. Frontiers in Human Neuroscience, 8(JULY), 1-11. https://doi.org/10.3389/fnhum.2014.00494

Biau, E., Fromont, L. A., \& Soto-Faraco, S. (2018). Beat Gestures and Syntactic Parsing: An ERP Study. Language Learning, 68(June 2018), 102-126. https://doi.org/10.1111/lang.12257 
735 Bishop, J., Kuo, G., \& Kim, B. (2020). Phonology, phonetics, and signal-extrinsic factors in the perception of prosodic prominence: Evidence from Rapid Prosody Transcription. Journal of Phonetics, 82, 100977. https://doi.org/10.1016/j.wocn.2020.100977

738

739

Blanco-Elorrieta, E., Ding, N., Pylkkänen, L., \& Poeppel, D. (2020). Understanding requires tracking: Noise and knowledge interact in bilingual comprehension. Journal of Cognitive Neuroscience, 32(10), 1975-1983. https://doi.org/10.1162/jocn_a_01610

Bolinger, D. (1972). Accent Is Predictable (If You're a Mind-Reader). Language, 48(3), 633. https://doi.org/10.2307/412039

Boucher, V. J. (2006). On the function of stress rhythms in speech: Evidence of a link with grouping effects on serial memory. Language and Speech, 49(4), 495-518. https://doi.org/10.1177/00238309060490040301

Brandt, A., Gebrian, M., \& Slevc, L. R. (2012). Music and early language acquisition. Frontiers in Psychology, 3(SEP), 1-17. https://doi.org/10.3389/fpsyg.2012.00327

Breen, M. (2014). Empirical investigations of the role of implicit prosody in sentence processing. Linguistics and Language Compass, 8(2), 37-50. https://doi.org/10.1111/lnc3.12061

Breen, M. (2015). Empirical Investigations of Implicit Prosody. In Explicit and Implicit Prosody in Sentence Processing. Springer.

Breen, M. (2018). Effects of metric hierarchy and rhyme predictability on word duration in The Cat in the Hat. Cognition, 174(January), 71-81. https://doi.org/10.1016/j.cognition.2018.01.014

Breen, M., \& Clifton, C. (2011). Stress matters: Effects of anticipated lexical stress on silent reading. Journal of Memory and Language, 64(2), 153-170. https://doi.org/10.1016/j.jml.2010.11.001 
758 Breen, M., \& Clifton, C. (2013). Stress matters revisited: A boundary change experiment. Quarterly Journal of Experimental Psychology, 66(10), 1896-1909. https://doi.org/10.1080/17470218.2013.766899

Breen, M., Fedorenko, E., Wagner, M., \& Gibson, E. (2010). Acoustic correlates of information structure. Language and Cognitive Processes, 25(7), 1044-1098.

Breen, M., Fitzroy, A. B., \& Oraa Ali, M. (2019). Event-Related Potential Evidence of Implicit

Brown, M., Salverda, A. P., Dilley, L. C., \& Tanenhaus, M. K. (2011). Expectations from preceding prosody influence segmentation in online sentence processing. Psychonomic

Brown, M., Salverda, A. P., Dilley, L. C., \& Tanenhaus, M. K. (2015). Metrical expectations

Buxó-Lugo, A., \& Watson, D. G. (2016). Evidence for the influence of syntax on prosodic

Brown, S., Pfordresher, P. Q., \& Chow, I. (2017). A musical model of speech rhythm. from preceding prosody influence perception of lexical stress. Journal of Experimental Psychology: Human Perception and Performance, 41(2), 306-323. Psychomusicology: Music, Mind, and Brain, 27(2), 95-112. parsing. Journal of Memory and Language, 90, 1-13. https://doi.org/10.1016/j.jml.2016.03.001

Calhoun, S. (2010). How does informativeness affect prosodic prominence? Language and Cognitive Processes, 25(7), 1099-1140. https://doi.org/10.1080/01690965.2010.491682 
781 Canette, L. H., Fiveash, A., Krzonowski, J., Corneyllie, A., Lalitte, P., Thompson, D., Trainor,

782 L., Bedoin, N., \& Tillmann, B. (2020). Regular rhythmic primes boost P600 in grammatical error processing in dyslexic adults and matched controls. Neuropsychologia, 138(July 2019). https://doi.org/10.1016/j.neuropsychologia.2019.107324

Cason, N., Astésano, C., \& Schön, D. (2015). Bridging music and speech rhythm: Rhythmic priming and audio-motor training affect speech perception. Acta Psychologica, 155, 4350. https://doi.org/10.1016/j.actpsy.2014.12.002

Cason, N., \& Schön, D. (2012). Rhythmic priming enhances the phonological processing of speech. Neuropsychologia, 50(11), 2652-2658. https://doi.org/10.1016/j.neuropsychologia.2012.07.018

Chern, A., Tillmann, B., Vaughan, C., \& Gordon, R. L. (2018). New evidence of a rhythmic

Cinque, G. (1993). A null theory of phrase and compound stress. Linguistic Inquiry, 24(2), 239297.

797 Cole, J. (2015). Prosody in context: A review. Language, Cognition and Neuroscience, 30(1-2), 1-31. https://doi.org/10.1080/23273798.2014.963130

799 Cole, J., Hualde, J. I., Smith, C. L., Eager, C., Mahrt, T., \& Napoleão de Souza, R. (2019). Sound, structure and meaning: The bases of prominence ratings in English, French and Spanish. Journal of Phonetics, 75, 113-147. https://doi.org/10.1016/j.wocn.2019.05.002

802 Cole, J., Mahrt, T., \& Roy, J. (2017). Crowd-sourcing prosodic annotation. Computer Speech 803 and Language, 45, 300-325. https://doi.org/10.1016/j.cs1.2017.02.008 
804 Cole, J., Mo, Y., \& Hasegawa-Johnson, M. (2010). Signal-based and expectation-based factors

805 in the perception of prosodic prominence. Laboratory Phonology, 1(2), 425-452.

806 https://doi.org/10.1515/labphon.2010.022

807 Colling, L. J., Noble, H. L., \& Goswami, U. (2017). Neural entrainment and sensorimotor 808 synchronization to the beat in children with developmental dyslexia: An EEG study.

809 Frontiers in Neuroscience, 11(JUL). https://doi.org/10.3389/fnins.2017.00360

810 Cumming, R., Wilson, A., Leong, V., Colling, L. J., \& Goswami, U. (2015). Awareness of

811 rhythm patterns in speech and music in children with specific language impairments.

812 Frontiers in Human Neuroscience, 9(DEC). https://doi.org/10.3389/fnhum.2015.00672

813 Cummins, F. (2009). Rhythm as an affordance for the entrainment of movement. Phonetica,

814 66(1-2), 15-28. https://doi.org/10.1159/000208928

815 Cummins, F. (2020). The Territory Between Speech and Song: A Joint Speech Perspective.

816 Music Perception: An Interdisciplinary Journal, 37(4), 347-358.

817 den Ouden, D. B., Dickey, M. W., Anderson, C., \& Christianson, K. (2016). Neural correlates of

818 early-closure garden-path processing: Effects of prosody and plausibility. Quarterly

$819 \quad$ Journal of Experimental Psychology, 69(5), 926-949.

820 https://doi.org/10.1080/17470218.2015.1028416

821 Dilley, L. C., \& McAuley, J. D. (2008). Distal prosodic context affects word segmentation and 822 lexical processing. Journal of Memory and Language, 59(3), 294-311.

823 https://doi.org/10.1016/j.jml.2008.06.006

824 Dilley, L. C., \& Pitt, M. A. (2010). Altering context speech rate can cause words to appear or 825 disappear. Psychological Science, 21(11), 1664-1670.

826 https://doi.org/10.1177/0956797610384743 
827 Ding, N., Patel, A. D., Chen, L., Butler, H., Luo, C., \& Poeppel, D. (2016). Temporal modulations in speech and music. Neuroscience and Biobehavioral Reviews. https://doi.org/10.1016/j.neubiorev.2017.02.011

Falk, S., \& Dalla Bella, S. (2016). It is better when expected: Aligning speech and motor rhythms enhances verbal processing. Language, Cognition and Neuroscience, 31(5),

Falk, S., \& Kello, C. T. (2017). Hierarchical organization in the temporal structure of infantdirect speech and song. Cognition, 163, 80-86.

Fiveash, A., Bedoin, N., Lalitte, P., \& Tillmann, B. (2020). Rhythmic priming of grammaticality

Falk, S., Müller, T., \& Dalla Bella, S. (2015). Non-verbal sensorimotor timing deficits in https://doi.org/10.1016/j.cognition.2017.02.017

Falk, S., Volpi-Moncorger, C., \& Dalla Bella, S. (2017). Auditory-motor rhythms and speech processing in French and German listeners. Frontiers in Psychology, 8(MAR), 1-14. https://doi.org/10.3389/fpsyg.2017.00395

Fedorenko, E., Patel, A., Casasanto, D., Winawer, J., \& Gibson, E. (2009). Structural integration in language and music: Evidence for a shared system. Memory and Cognition, 37(1), 1-9. judgments in children: Duration matters. Journal of Experimental Child Psychology. In Press, 197, 104885. https://doi.org/10.1016/j.jecp.2020.104885

Fiveash, A., Schön, D., Canette, L. H., Morillon, B., Bedoin, N., \& Tillmann, B. (2020). A stimulus-brain coupling analysis of regular and irregular rhythms in adults with dyslexia 
and controls. Brain and Cognition, 140(January), 105531. https://doi.org/10.1016/j.bandc.2020.105531

852 Fodor, J. D. (2002). Psycholinguistics cannot escape prosody. Proceedings of the 1st International Conference on Speech Prosody, October, 83-88.

854 François, C., Chobert, J., Besson, M., \& Schön, D. (2013). Music training for the development of 855 speech segmentation. Cerebral Cortex, 23(9), 2038-2043. https://doi.org/10.1093/cercor/bhs180

857 Ghitza, O. (2017). Acoustic-driven delta rhythms as prosodic markers. Language, Cognition and 858 Neuroscience, 32(5), 545-561. https://doi.org/10.1080/23273798.2016.1232419

859 Gibson, E. (1998). Linguistic complexity: Locality of syntactic dependencies. Cognition, 68(1), 1-76. https://doi.org/10.1016/S0010-0277(98)00034-1

861

Gibson, E., Desmet, T., Grodner, D., Watson, D., \& Ko, K. (2005). Reading relative clauses in English. Cognitive Linguistics, 16(2), 313-353.

863 https://doi.org/10.1515/cogl.2005.16.2.313

864 Goldstone, R. L., de Leeuw, J. R., \& Landy, D. H. (2015). Fitting perception in and to cognition. 865 Cognition, 135, 24-29. https://doi.org/10.1016/j.cognition.2014.11.027

Gordon, R. L., Magne, C. L., \& Large, E. W. (2011). EEG correlates of song prosody: A new 867 look at the relationship between linguistic and musical rhythm. Frontiers in Psychology, 2(NOV), 1-13. https://doi.org/10.3389/fpsyg.2011.00352

869 Gordon, R. L., Shivers, C. M., Wieland, E. A., Kotz, S. A., Yoder, P. J., \& Devin Mcauley, J. 870 (2015). Musical rhythm discrimination explains individual differences in grammar skills in children. Developmental Science, 18(4), 635-644. https://doi.org/10.1111/desc.12230 
872 Gorin, S., Mengal, P., \& Majerus, S. (2018). A comparison of serial order short-term memory

873 effects across verbal and musical domains. Memory and Cognition, 46(3), 464-481.

874 https://doi.org/10.3758/s13421-017-0778-0

875 Goswami, U., \& Leong, V. (2013). Speech rhythm and temporal structure: Converging perspectives? Laboratory Phonology, 4(1), 67-92. https://doi.org/10.1515/lp-2013-0004

877 Gow, D. W., \& Gordon, P. C. (1993). Coming to Terms with Stress: Effects of Stress Location in Sentence Processing. Journal of Psycholinguistic Research, 22(6), 545-578.

Hartley, T., Hurlstone, M. J., \& Hitch, G. J. (2016). Effects of rhythm on memory for spoken sequences: A model and tests of its stimulus-driven mechanism. Cognitive Psychology, 87, 135-178. https://doi.org/10.1016/j.cogpsych.2016.05.001

Hawkins, S. (2014). Situational influences on rhythmicity in speech, music, and their interaction. Philosophical Transactions of the Royal Society B: Biological Sciences, 369(1658).

Henry, M. J., \& Herrmann, B. (2014). Low-Frequency Neural Oscillations Support Dynamic Attending in Temporal Context. Timing and Time Perception, 2(1), 62-86.

Hickey, P., Merseal, H., Patel, A. D., \& Race, E. (2020). Memory in time: Neural tracking of low-frequency rhythm dynamically modulates memory formation. NeuroImage, 116693. https://doi.org/10.1016/j.neuroimage.2020.116693

892

Holle, H., Obermeier, C., Schmidt-Kassow, M., Friederici, A. D., Ward, J., \& Gunter, T. C. (2012). Gesture facilitates the syntactic analysis of speech. Frontiers in Psychology, 3(MAR), 1-12. https://doi.org/10.3389/fpsyg.2012.00074 
894 Hurlstone, M. J. (2019). Functional similarities and differences between the coding of positional 895 information in verbal and spatial short-term order memory. Memory, 27(2), 147-162. https://doi.org/10.1080/09658211.2018.1495235

Huss, M., Verney, J. P., Fosker, T., Mead, N., \& Goswami, U. (2011). Music, rhythm, rise time perception and developmental dyslexia: Perception of musical meter predicts reading and phonology. Cortex, 47(6), 674-689. https://doi.org/10.1016/j.cortex.2010.07.010

Jones, A., \& Ward, E. (2019). Rhythic Temporal Structure at Encoding Enhances Recognition Memory. Journal of Cognitive Neuroscience, 31(10), 1549-1562. https://doi.org/10.1162/jocn

Kaufeld, G., Naumann, W., Meyer, A. S., Bosker, H. R., \& Martin, A. E. (2019). Contextual speech rate influences morphosyntactic prediction and integration. Language, Cognition and Neuroscience, O(0), 1-16. https://doi.org/10.1080/23273798.2019.1701691

Kentner, G. (2012). Linguistic rhythm guides parsing decisions in written sentence comprehension. Cognition, 123(1), 1-20. https://doi.org/10.1016/j.cognition.2011.11.012

Kentner, G., \& Vasishth, S. (2016). Prosodic focus marking in silent reading: Effects of discourse context and rhythm. Frontiers in Psychology, 7(MAR), 1-19. https://doi.org/10.3389/fpsyg.2016.00319

Kjelgaard, M. M., \& Speer, S. R. (1999). Prosodic Facilitation and Interference in the Resolution

914 Kotz, S. A., \& Schmidt-Kassow, M. (2015). Basal ganglia contribution to rule expectancy and 915 temporal predictability in speech. Cortex, 68, 48-60.

916 https://doi.org/10.1016/j.cortex.2015.02.021 
917 Krahmer, E., \& Swerts, M. (2007). The effects of visual beats on prosodic prominence: Acoustic

918 analyses, auditory perception and visual perception. Journal of Memory and Language,

919 57(3), 396-414. https://doi.org/10.1016/j.jml.2007.06.005

920 Ladd, R. D. (2008). Intonational Phonology (Second Edi). Cambridge University Press.

921 Lakatos, P., Karmos, G., Mehta, A. D., Ulbert, I., \& Schroeder, C. E. (2008). Entrainment of

922 neuronal oscillations as a mechanism of attentional selection. Science (New York, N.Y.),

923 320(5872), 110-113. https://doi.org/10.1126/science.1154735

924 Large, E. W., \& Jones, M. R. (1999). The dynamics of attending: How people track time-varying

925 events. Psychological Review, 106(1), 119-159. https://doi.org/10.1037/0033-

$926 \quad 295 X .106 .1 .119$

927 Lee, C. S., \& Todd, N. P. M. A. (2004). Towards an auditory account of speech rhythm:

928 Application of a model of the auditory "primal sketch" to two multi-language corpora.

929 Cognition, 93(3), 225-254. https://doi.org/10.1016/j.cognition.2003.10.012

930 Lerdahl, F., \& Jackendoff, R. (1983). A Generative Theory of Tonal Music. MIT Press.

931 Levy, R. (2008). Expectation-based syntactic comprehension. Cognition, 106(3), 1126-1177.

932 https://doi.org/10.1016/j.cognition.2007.05.006

933 Levy, R., Fedorenko, E., Breen, M., \& Gibson, E. (2012). The processing of extraposed

934 structures in English. Cognition, 122(1), 12-36.

935 https://doi.org/10.1016/j.cognition.2011.07.012

936 London, J. (2004). Hearing in time: Psychological aspects of musical meter. Oxford University 937 Press. 
938 Lowder, M. W., \& Gordon, P. C. (2014). Effects of animacy and noun-phrase relatedness on the 939 processing of complex sentences. Memory and Cognition, 42(5), 794-805.

940 https://doi.org/10.3758/s13421-013-0393-7

941 Martin, J. G. (1972). Rhythmic (hierarchical) versus serial structure in speech and other

942 behavior. Psychological Review, 79(6), 487-509. https://doi.org/10.1037/h0033467

943 Mates, J., Müller, U., Radil, T., \& Pöppel, E. (1994). Temporal integration in sensorimotor 944 synchronization. Journal of Cognitive Neuroscience, 6(4), 332-340.

945 https://doi.org/10.1162/jocn.1994.6.4.332

946 Mathias, B., Pfordresher, P. Q., \& Palmer, C. (2015). Context and meter enhance long-range

947 planning in music performance. Frontiers in Human Neuroscience, 8(JAN), 1-15.

948 https://doi.org/10.3389/fnhum.2014.01040

949 Meyer, L., Henry, M. J., Gaston, P., Schmuck, N., \& Friederici, A. D. (2017). Linguistic bias

950 modulates interpretation of speech via neural delta-band oscillations. Cerebral Cortex, 27(9), 4293-4302. https://doi.org/10.1093/cercor/bhw228

952 Morillon, B., Arnal, L. H., Schroeder, C. E., \& Keitel, A. (2019). Prominence of delta oscillatory

953 rhythms in the motor cortex and their relevance for auditory and speech perception.

$954 \quad$ Neuroscience and Biobehavioral Reviews.

955 https://doi.org/10.1016/j.neubiorev.2019.09.012

956 Morillon, B., \& Baillet, S. (2017). Motor origin of temporal predictions in auditory attention.

957 Proceedings of the National Academy of Sciences, 201705373.

958 https://doi.org/10.1073/pnas.1705373114

959 Morrill, T. H., Dilley, L. C., McAuley, J. D., \& Pitt, M. A. (2014). Distal rhythm influences

960 whether or not listeners hear a word in continuous speech: Support for a perceptual 
grouping hypothesis. Cognition, 131(1), 69-74.

Moser, C. J., Lee-rubin, H., Bainbridge, C. M., Atwood, S., Simson, J., Knox, D., Galbarczyk, A., Jasienska, G., Ross, C. T., Neff, M. B., Martin, A., Cirelli, K., Trehub, S. E., Song, J., Kim, M., Schachner, A., Vardy, T. A., Quentin, D., \& Mehr, S. A. (2020). Acoustic regularities in infant-directed vocalizations across cultures.

967 Newman, S. D., Lee, D., \& Ratliff, K. L. (2009). Off-line sentence processing: What is involved in answering a comprehension probe? Human Brain Mapping, 30(8), 2499-2511.

Ng, H. L. H., \& Maybery, M. T. (2002). Grouping in short-term verbal memory: Is position coded temporally? Quarterly Journal of Experimental Psychology Section A: Human

Niebuhr, O. (2009). F0-based rhythm effects on the perception of local syllable prominence. Phonetica, 66(1-2), 95-112. https://doi.org/10.1159/000208933

Pitt, M. A., \& Samuel, A. G. (1990). The Use of Rhythm in Attending to Speech. Journal of Experimental Psychology: Human Perception and Performance, 16(3), 564-573. https://doi.org/10.1037/0096-1523.16.3.564 
984 Prince, A. (1983). Relating to the Grid. Linguistic Inquiry, 14(1), 19-100. https://doi.org/""

985 Quené, H., \& Port, R. F. (2005). Effects of timing regularity and metrical expectancy on spoken-

986 word perception. Phonetica, 62(1), 1-13. https://doi.org/10.1159/000087222

987 Richards, S., \& Goswami, U. (2019). Impaired Recognition of Metrical and Syntactic Boundaries in Children with Developmental Language Disorders. Brain Sciences, 9(2), 33. https://doi.org/10.3390/brainsci9020033

Rimmele, J. M., Morillon, B., Poeppel, D., \& Arnal, L. H. (2018). Proactive Sensing of Periodic and Aperiodic Auditory Patterns. Trends in Cognitive Sciences, 22(10), 870-882. https://doi.org/10.1016/j.tics.2018.08.003

Rimmele, J. M., Poeppel, D., \& Ghitza, O. (2020). Acoustically driven cortical delta oscillations

Robinson, G. M., \& Robinson, G. M. (1977). Rhythmic Organization in Speech Processing. 3(1), 83-91. underpin perceptual chunking. BioRxiv, 2020.05.16.099432. https://doi.org/10.1101/2020.05.16.099432

Rothermich, K., \& Kotz, S. A. (2013). Predictions in speech comprehension: FMRI evidence on 1002

Roncaglia-Denissen, M. P., Schmidt-Kassow, M., \& Kotz, S. A. (2013). Speech Rhythm Facilitates Syntactic Ambiguity Resolution: ERP Evidence. PLoS ONE, 8(2), 1-9. https://doi.org/10.1371/journal.pone.0056000

1004

Rothermich, K., Schmidt-Kassow, M., \& Kotz, S. A. (2012). Rhythm's gonna get you: Regular 1005 meter facilitates semantic sentence processing. Neuropsychologia, 50(2), 232-244. https://doi.org/10.1016/j.neuropsychologia.2011.10.025 
1007 Ryan, J. (1969). Grouping and short-term memory: Different means and patterns of grouping.

1008 The Quarterly Journal of Experimental Psychology, 21(2), 137-147.

1009 https://doi.org/10.1080/14640746908400206

1010 Schmidt-Kassow, M., \& Kotz, S. A. (2008). Event-related Brain Potentials Suggest a Late

1011 Interaction of Meter and Syntax in the P600. Journal of Cognitive Neuroscience, 1693-

$1012 \quad$ 1708. https://doi.org/10.1162/jocn.2008.21153

1013 Schön, D., Boyer, M., Moreno, S., Besson, M., Peretz, I., \& Kolinsky, R. (2008). Songs as an aid

1014 for language acquisition. Cognition, 106(2), 975-983.

1015 https://doi.org/10.1016/j.cognition.2007.03.005

1016 Schremm, A., Horne, M., \& Roll, M. (2015). Brain responses to syntax constrained by time-

1017 driven implicit prosodic phrases. Journal of Neurolinguistics, 35, 68-84.

1018 https://doi.org/10.1016/j.jneuroling.2015.03.002

1019 Schremm, A., Horne, M., \& Roll, M. (2016). Time-Driven Effects on Processing Relative

$1020 \quad$ Clauses. Journal of Psycholinguistic Research, 45(5), 1033-1044.

$1021 \quad$ https://doi.org/10.1007/s10936-015-9391-1

1022 Selkirk, E. (2011). The Syntax-Phonology Interface. In J. Goldsmith, J. Riggle, \& A. Yu (Eds.), 1023 The Handbook of Phonological Theory.

1024 Stefaniak, J. D., Lambon Ralph, M. A., De Dios Perez, B., Griffiths, T. D., \& Grube, M. (2021).

1025 Auditory beat perception is related to speech output fluency in post-stroke aphasia.

1026 Scientific Reports, 11(1), 3168. https://doi.org/10.1038/s41598-021-82809-w

1027 Thavabalasingam, S., O’Neil, E. B., Zeng, Z., \& Lee, A. C. H. (2016). Recognition memory is

1028 improved by a structured temporal framework during encoding. Frontiers in Psychology,

1029 6(JAN), 1-11. https://doi.org/10.3389/fpsyg.2015.02062 
1030 Tilsen, S. (2011). Metrical regularity facilitates speech planning and production. Laboratory Phonology, 2(1), 185-218. https://doi.org/10.1515/labphon.2011.006

1032 Tilsen, S. (2019). Space and time in models of speech rhythm. Annals of the New York Academy 1033 of Sciences, 1453, 47-66. https://doi.org/10.1111/nyas.14102

1034 Tilsen, S., \& Arvaniti, A. (2013). Speech rhythm analysis with decomposition of the amplitude 1035 1036 envelope: Characterizing rhythmic patterns within and across languages. The Journal of the Acoustical Society of America, 134(1), 628-639. https://doi.org/10.1121/1.4807565

1037 Toyomura, A., Fujii, T., \& Kuriki, S. (2015). Effect of an 8-week practice of externally triggered 1038 speech on basal ganglia activity of stuttering and fluent speakers. NeuroImage, 109, 458468. https://doi.org/10.1016/j.neuroimage.2015.01.024

Vanden, C. M., Nederlanden, B. Der, Joanisse, M., \& Grahn, J. A. (2020). Music as a scaffold for listening to speech: Better neural phase-locking to song than speech. NeuroImage, 116767. https://doi.org/10.1016/j.neuroimage.2020.116767

Wagner, M. (2010). Prosody and recursion in coordinate structures and beyond. Natural Language and Linguistic Theory, 28(1), 183-237. https://doi.org/10.1007/s11049-0099086-0

Wagner, M., \& McAuliffe, M. (2019). The effect of focus prominence on phrasing. Journal of Phonetics, 77, 100930. https://doi.org/10.1016/j.wocn.2019.100930 perception deficit in children who stutter. Brain and Language, 144, $26-34$. https://doi.org/10.1016/j.bandl.2015.03.008 
Proceedings of the National Academy of Sciences, 111(40), 14559-14564. https://doi.org/10.1073/pnas.1406219111

Zhou, P., \& Christianson, K. (2016). I "hear” what you're "saying": Auditory perceptual simulation, reading speed, and reading comprehension. Quarterly Journal of Experimental Psychology, 69(5), 972-995.

https://doi.org/10.1080/17470218.2015.1018282

Zhou, P., Garnsey, S., \& Christianson, K. (2019). Is imagining a voice like listening to it?

Evidence from ERPs. Cognition, 182(October 2018), 227-241. https://doi.org/10.1016/j.cognition.2018.10.014

Zhou, P., Yao, Y., \& Christianson, K. (2018). When structure competes with semantics: Reading Chinese relative clauses. Collabra: Psychology, 4(1), 1-16. https://doi.org/10.1525/collabra.131

Zubizarreta, M. L. (2014). Nuclear Stress and Information Structure. In C. Féry \& S. Ishihara (Eds.), The Oxford Handbook of Information Structure (Vol. 1, pp. 1-24). https://doi.org/10.1093/oxfordhb/9780199642670.013.008

\section{Supplementary figures}




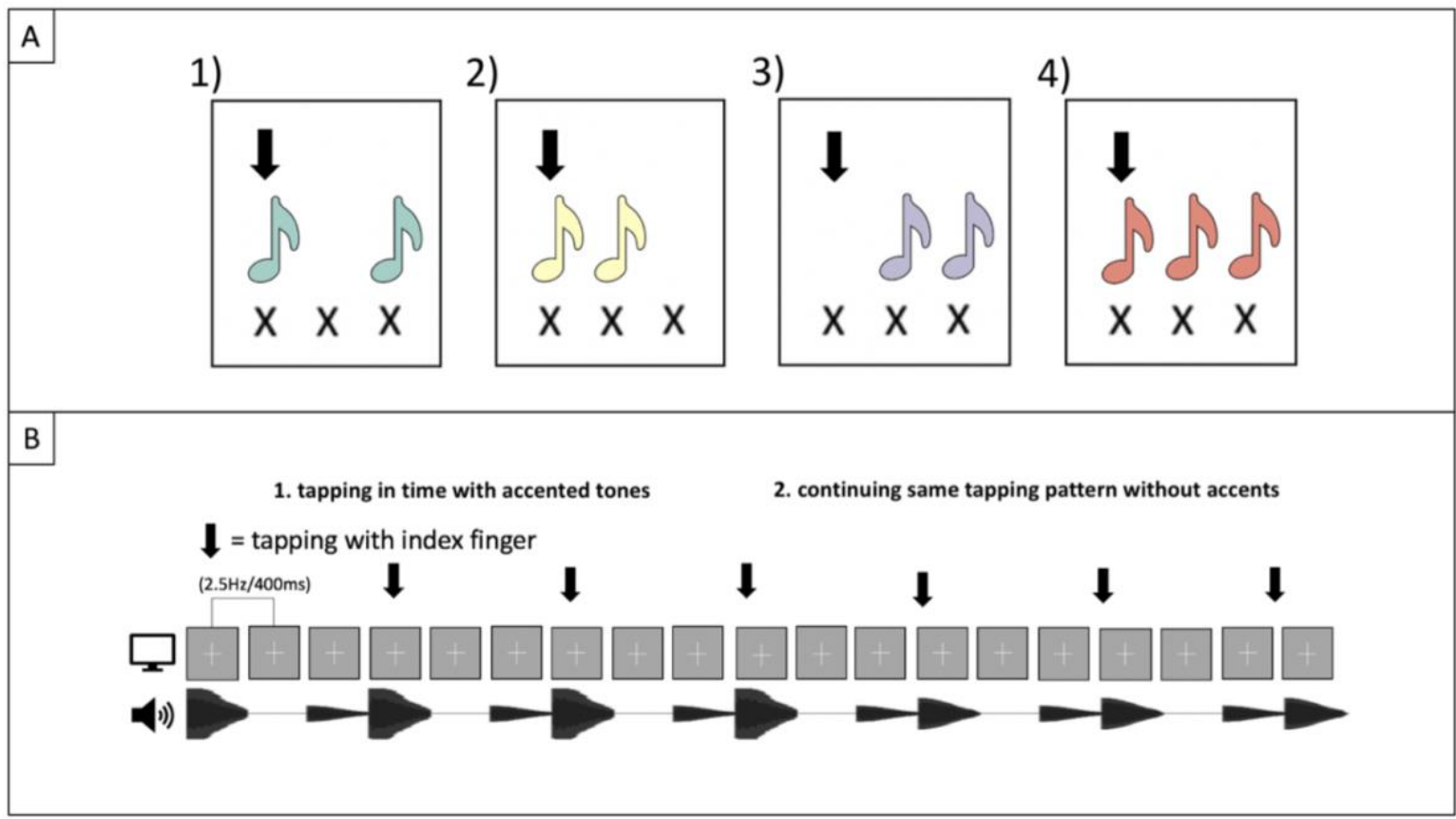

1073

1075

1076

1077

1078

Supplementary Figure 1: A) The control rhythms represented four rhythmic patterns that corresponded to 1) the object-extracted sentence rhythm of a continuous triplet (which sounds identical regardless of metrical alignment; it is symmetric), and 2) the three different ways of aligning the subject-extracted sentence rhythm (this rhythm had three different versions because it is not symmetric under metrical groups of three). B) trial schematic for the non-linguistic rhythm section of experiment 2 (using rhythm 1 as an example). 